\title{
Diversity within the current algal species Prototheca zopfii: a proposal for two Prototheca zopfii genotypes and description of a novel species, Prototheca blaschkeae sp. nov.
}

\author{
Correspondence \\ Uwe Roesler \\ roesler@vetmed.uni-leipzig.de
}

\author{
Uwe Roesler, ${ }^{1}$ Asia Möller, ${ }^{1}$ Andreas Hensel, ${ }^{1,2}$ Daniela Baumann ${ }^{1}$ \\ and Uwe Truyen ${ }^{1}$ \\ ${ }^{1}$ Institute of Animal Hygiene and Veterinary Public Health, Faculty of Veterinary Medicine, \\ University of Leipzig, An den Tierkliniken 1, D-04103 Leipzig, Germany \\ ${ }^{2}$ Federal Institute for Risk Assessment, D-14195 Berlin, Germany
}

\begin{abstract}
In order to clarify the intraspecies taxonomic position of the non-photosynthetic algal species Prototheca zopfii, as well as the aetiology of bovine mammary protothecosis, a selection of $P$. zopfii strains isolated from clinical cases of protothecal mastitis and from various environmental habitats was characterized using a polyphasic molecular approach. Based on sequence analysis of the 18S rRNA gene, which showed distinct differences between the three currently known biotypes or 'variants', specific oligonucleotides were designed and used in biotype-specific PCRs. Furthermore, the pattern of cellular fatty acids was evaluated. Typing by means of these techniques revealed that the previously defined biotypes of $P$. zopfii were clearly different. Based on sequence analysis, the pattern of fatty acids and physiological characteristics, it is proposed that biotype 3 should be reclassified as representing a novel species, Prototheca blaschkeae sp. nov. (type strain, RZIII- $3^{\top}=$ SAG $2064^{\top}$ ). Furthermore, it is proposed that $P$. zopfii merits reclassification as a species comprising at least two genotypes that in future could probably be considered to represent two subspecies.
\end{abstract}

Colourless algae of the genus Prototheca of the family Chlorellaceae have been identified as causative agents of infections in humans and animals. The taxonomic status of Prototheca has evolved over several decades, and four species are currently assigned to the genus: Prototheca zopfi, Prototheca wickerhamii, Prototheca stagnora and Prototheca ulmea. A fifth not generally accepted species was assigned as Prototheca moriformis (Arnold \& Ahearn, 1972; Krüger, 1894; Pore, 1985, 1986). This species is genetically and biochemically very similar to $P$. zopfii; otherwise, there is a marked heterogeneity between strains of $P$. moriformis (Pore, 1985; Ueno et al., 2003).

In addition, three biotypes or so-called 'variants' of P. zopfii have been defined, based on phenotypic characteristics (Roesler et al., 2003). Auxanographical and biochemical investigations of isolates from various habitats revealed that

Abbreviations: ML, maximum-likelihood; NJ, neighbour-joining.

The GenBank/EMBL/DDBJ accession number for the 18S rRNA gene sequence of Prototheca blaschkeae sp. nov. SAG $2064^{\top}$ is AY973041.

A figure showing aligned target sequences of specific oligonucleotides for $P$. zopfii genotype 1, $P$. zopfii genotype 2 and $P$. blaschkeae sp. nov. is available as supplementary material in IJSEM Online. all bovine mastitis isolates (biotype 2) showed a delayed assimilation of galactose and an increased assimilation of amino acids, compared with isolates of biotype 1 from cattle liquid manure (Blaschke-Hellmessen et al., 1985; Roesler et al., 2003). Isolates from swine farms (biotype 3 ) were not capable of assimilating glycerol or the majority of the amino acids tested. Furthermore, serological typing by immunoblotting revealed major differences in the pattern of immunogenic structures between the three P. zopfii biotypes (Roesler et al., 2003). Comparative investigations by means of Fourier-transformed infra-red spectroscopy also showed distinct differences between variant 3 and the other two variants. However, discrimination of variants was not possible between strains assigned to variant 1 or 2 (Schmalreck et al., 1998).

The present study involved the comparative investigation of the three biotypes by means of sequence analysis of the $18 \mathrm{~S}$ rRNA gene and determination of cellular fatty acids. The data showed that the three biotypes clearly differ in both the small-subunit (18S) rRNA gene and cellular fatty acid composition. Furthermore, the sequences of members of the current biotype 3 differ markedly from those of the other described Prototheca species. Therefore, a novel species, 
Prototheca blaschkeae sp. nov., is proposed for the present biotype 3. In addition, two novel genotypes 1 and 2 are proposed for the current biotypes 1 and 2 of P. zopfii.

For this study, P. zopfii isolates from bovine mastitis from different herds (RZII-2 and RZII-3), from different cattle liquid manure and cattle barns (RZI-1, RZI-2 and RZI-3), from different piggeries (RZIII-1 and RZIII-2) and from a human case of onychomycosis (RZIII- $3^{\mathrm{T}}$ ) were provided by the Institute of Microbiology and Hygiene of the Technical University of Dresden, Dresden, Germany. These strains were originally isolated by R. Blaschke-Hellmessen. In addition, one strain (LZ 5) was isolated from a clinical case of severe mastitis in a lactating cow. More recently, this strain has been used as an ELISA antigen for the serological diagnosis of bovine protothecal mastitis (Roesler et al., 2001). Three of these strains were deposited at the Stammsammlung für Algenkulturen (SAG), University of Göttingen, Göttingen, Germany. Strain RZI-3 was deposited as SAG 2063, LZ 5 as SAG 2021 and RZIII-3 ${ }^{\mathrm{T}}$ as SAG $2064^{\mathrm{T}}$. In addition, P. zopfii strain SAG $263-4^{\mathrm{T}}$, which was isolated from a human case of enteropathy, was also used for the comparative investigation. The strains investigated were biochemically assigned to biotype 1 (RZI-1, RZI-2 and SAG 2063), biotype 2 (SAG 263-4 ${ }^{\mathrm{T}}$, SAG 2021, RZII-2 and RZII3 ) and biotype 3 (RZIII-1, RZIII-2 and SAG $2064^{\mathrm{T}}$ ) of $P$. zopfii (Blaschke-Hellmessen et al., 1985; Roesler et al., 2003). In addition, two other strains (from the Central Bureau voor Schimmelcultures, Utrecht, The Netherlands) were used for biochemical discrimination: P. stagnora CBS 605.66 and P. wickerhamii CBS 157.74. Biochemical identification of Prototheca species and differentiation into biotypes of $P$. zopfii were performed as described previously (Roesler et al., 2003) by using the microbial identification system BBL Crystal (Becton Dickinson). Two kits were utilized, BBL Crystal Enteric/Nonfermenter and BBL Crystal Gram positive. In total, 50 carbon and nitrogen sources were tested with these two kits for each strain. The test panels were incubated in a humid chamber at $37^{\circ} \mathrm{C}$ for $48 \mathrm{~h}$. Biochemical characteristics that discriminated Prototheca species are shown in Table 1.

With the aim of achieving intraspecies and interspecies differentiation, the strains were compared by means of their cellular fatty acid pattern, sequence analysis of the highly conserved $18 \mathrm{~S}$ rRNA genes and by biotype-specific PCR.

The Prototheca strains investigated were cultured aerobically on Sabouraud dextrose agar plates for $48 \mathrm{~h}$. Fatty acid methyl esters (FAMEs) were extracted from $100 \mathrm{mg}$ biomass of the isolates, as described by Biedermann et al. (2004) with minor modifications. The extraction was performed with n-hexane/methanol (1:1, by vol.), with stirring over a 60 min period. Subsequently, the FAMEs were separated by GC/MS using an Agilent $6890 \mathrm{~N}$ gas chromatograph and an Agilent 5973N mass selective detector (Agilent Technologies). MSD Productivity Enhanced ChemStation software (Agilent Technologies) was used to acquire the MS
Table 1. Characteristics that discriminate Prototheca species

Strains: 1, P. stagnora CBS 605.66; 2, P. wickerhamii CBS 157.74; 3, P. zopfii genotype 1 SAG 2063; 4, P. zopfii genotype 2 SAG 2021; 5, P. blaschkeae sp. nov. SAG $2064^{\mathrm{T}}$. Nutrient utilization is scored as: +, utilization; -, no utilization; $(-)$, utilization after 96 h. Fatty acids shown are only those that differentiate $P$. zopfii genotypes and P. blaschkeae sp. nov. (out of 21 detected). Values given are means plus SEM (in parentheses). NI, Not investigated.

\begin{tabular}{|c|c|c|c|c|c|}
\hline Characteristic & 1 & 2 & 3 & 4 & 5 \\
\hline \multicolumn{6}{|c|}{ Nutrient utilization*: } \\
\hline Galactose $^{a}$ & $(-)$ & + & + & $(-)$ & + \\
\hline Glycerol $^{a}$ & + & + & + & + & - \\
\hline Arginine $^{a}$ & + & + & + & + & - \\
\hline Lysine $^{a}$ & $(-)$ & + & - & + & - \\
\hline Fructose $^{b}$ & + & + & + & + & + \\
\hline Trehalose $^{b}$ & - & + & - & - & - \\
\hline Capsule & + & - & - & - & - \\
\hline \multicolumn{6}{|l|}{ Fatty acid (\%): } \\
\hline $\mathrm{C}_{16: 0}$ & NI & NI & $\begin{array}{l}23 \cdot 14 \\
(0 \cdot 26)\end{array}$ & $\begin{array}{c}23 \cdot 3 \\
(0 \cdot 89)\end{array}$ & $\begin{array}{c}15 \cdot 58 \\
(0 \cdot 42) \dagger\end{array}$ \\
\hline $\mathrm{C}_{16: 1}$ & NI & NI & $\begin{array}{c}0 \cdot 38 \\
(0 \cdot 02)\end{array}$ & $\begin{array}{c}0 \cdot 28 \\
(0 \cdot 02)\end{array}$ & $\begin{array}{c}1 \cdot 45 \\
(0 \cdot 06) \dagger\end{array}$ \\
\hline $\mathrm{C}_{17: 2}-\mathrm{CP}_{17: 0}$ & $\mathrm{NI}$ & NI & $\begin{array}{c}0 \cdot 36 \\
(0 \cdot 09)\end{array}$ & $\begin{array}{c}0 \cdot 12 \\
(0 \cdot 05)\end{array}$ & $\begin{array}{c}1 \cdot 26 \\
(0 \cdot 16) \dagger\end{array}$ \\
\hline $\mathrm{C}_{18: 1}$ & NI & NI & $\begin{array}{l}24 \cdot 46 \\
(1 \cdot 18)\end{array}$ & $\begin{array}{l}29 \cdot 02 \\
(1 \cdot 01)\end{array}$ & $\begin{array}{c}39 \cdot 94 \\
(1 \cdot 22) \dagger\end{array}$ \\
\hline $\mathrm{C}_{20: 2}$ & NI & NI & $\begin{array}{c}0 \cdot 02 \\
(0 \cdot 02)\end{array}$ & $\begin{array}{c}0 \cdot 36 \\
(0 \cdot 02) \dagger\end{array}$ & $0 \cdot 0$ \\
\hline
\end{tabular}

${ }^{\star}$ Determined after $48 \mathrm{~h}$ using BBL Crystal kits: $a$, Enteric/NF; $b$, Gram positive.

$\dagger$ Significantly different $(P<0 \cdot 01)$ from the other strains investigated.

data. The FAMEs were then identified using the NIST 98 mass spectral library (Agilent Technologies). Cultivation followed by analysis was repeated five times. These fatty acid analyses showed that there were clear differences between the current biotypes of $P$. zopfii (Table 1). Essentially, the differences detected were a significantly $(P<0 \cdot 01)$ increased amount of eicosadienoic acid $\left(\mathrm{C}_{20: 2}\right)$ in biotype 2 compared with biotype 1 and with biotype 3 that does not contain this fatty acid, and significantly increased amounts of palmitic acid $\left(\mathrm{C}_{16: 0}\right)$, palmitoleic acid $\left(\mathrm{C}_{16: 1}\right)$, linoleic acid-cyclopropane complex $\left(\mathrm{C}_{17: 2}-\mathrm{CP}_{17: 0}\right)$ and oleic acid $\left(\mathrm{C}_{18: 1}\right)$ in biotype 3 compared with biotypes 1 and 2 .

Preparation of genomic DNA was carried out as described previously (Roesler et al., 2001). In brief, the algal cells were ultrasonicated and the DNA was obtained using a DNeasy Plant kit (Qiagen). For sequence analysis of the 18S rRNA gene, four overlapping fragments of the entire gene were amplified using the primer pairs Proto18-1f (5'-GATACAAGACCGACCGCCTTT- $\left.3^{\prime}\right)$ and Proto $18-1 \mathrm{r}\left(5^{\prime}\right.$-AAACCGTTAGCTTTACTCCC-3'), Proto18-2f (5' -CGCGCAAA- 
TTACCCAATCC-3') and Proto18-2r (5'-TGAGACCGGACAGGGCAA-3'), Proto18-3f ( $5^{\prime}$-CCTCTGCAGGACCGGAGTAA-3') and Proto18-3r (5' -TGTACCGCTCCTAACTGTCTA- $3^{\prime}$ ), and Proto 18-4f ( $5^{\prime}$-GACATGGCGAGGATTGACAGA-3') and Proto18-4r (5'-AGGATGGCTAACCCACACGA-3').

Based on results of the alignment of the $18 \mathrm{~S}$ rRNA gene sequences the following oligonucleotides were used for biotype-specific PCR (Fig. 1): PZGT 1/r (5'-GCCAAGGCCCCCCGAAG-3') for biotype 1, PZGT 2/r (5'-GTCGGCGGGGCAAAAGC-3') for biotype 2 and PZGT 3/r (5'GTTGGCCCGGCATCGCT- $3^{\prime}$ ) for biotype 3 . These specific reverse primers were used with the following oligonucleotides that also acted as part of the internal amplification controls: Proto18-4f for primers PZGT 1/r and PZGT 2/r; and PZGT 3-IK/f ( $5^{\prime}$-CAGGGTTCGATTCCGGAGAG-3') for oligonucleotide PZGT 3/r. The alignment with the target regions of these oligonucleotides is available as Supplementary Fig. S1 in IJSEM Online.

The following oligonucleotides served as internal amplification controls: Proto18-4f and Proto18-4r for biotypes 1 and 2; PZGT 3-IK/f and PZGT 3-IK/R (5'-GAATTACCGCGGCTGCTGG-3') for biotype 3. PCR was carried out using Mastermix $1 \cdot 1 \times$ ReddyMix (Abgene) in a Tpersonal thermal cycler (Whatman Biometra). Cycle conditions were $30 \mathrm{~s}$ denaturation at $94{ }^{\circ} \mathrm{C}$ and $40 \mathrm{~s}$ extension at $72^{\circ} \mathrm{C}$. Annealing conditions were chosen based on the $\mathrm{G}+\mathrm{C}$ content of the corresponding oligonucleotides $\left(58^{\circ} \mathrm{C}\right.$ for biotypes 1 and 2 ; $63{ }^{\circ} \mathrm{C}$ for biotype 3 ). The products were analysed on a $1 \%$ $(\mathrm{w} / \mathrm{v})$ agarose gel and purified using a PCR Purification kit (Qiagen). They were then sequenced using an ABI Prism 3100 Avant sequencer (Applied Biosystems) using the dideoxy-chain termination method. The sequences were analysed using DNA Sequencing analysis software v5.2 (Applied Biosystems).

To examine phylogenetic relationships, the sequences were first aligned using CLUSTAL W multiple sequence alignment (Thompson et al., 1994), with the MegAlign module of the LASERGENE software package (DNASTAR). Available reference sequences (GenBank) of Prototheca species were included. Phylogenetic analyses were performed using TREECON (Van de Peer \& De Wachter, 1994) and TREEFINDER (Jobb et al., 2004). The aligned sequences were subjected to genetic distance calculation using the twoparameter method of Kimura (1980) and to phylogenetic analysis using the neighbour-joining (NJ) method (Saitou \& Nei, 1987) with TREECON and the maximum-likelihood (ML) method with TREEFINDER. Bootstrap analyses were performed on 1000 random samples (100 samples for ML) taken from multiple alignments, as described by Felsenstein (1985).

Based on the results of the sequence analysis, the current biotypes of $P$. zopfii should be reclassified as genotypes 1 (biotype 1) and 2 (biotype 2), and as a novel species, $P$. blaschkeae sp. nov. (biotype 3).
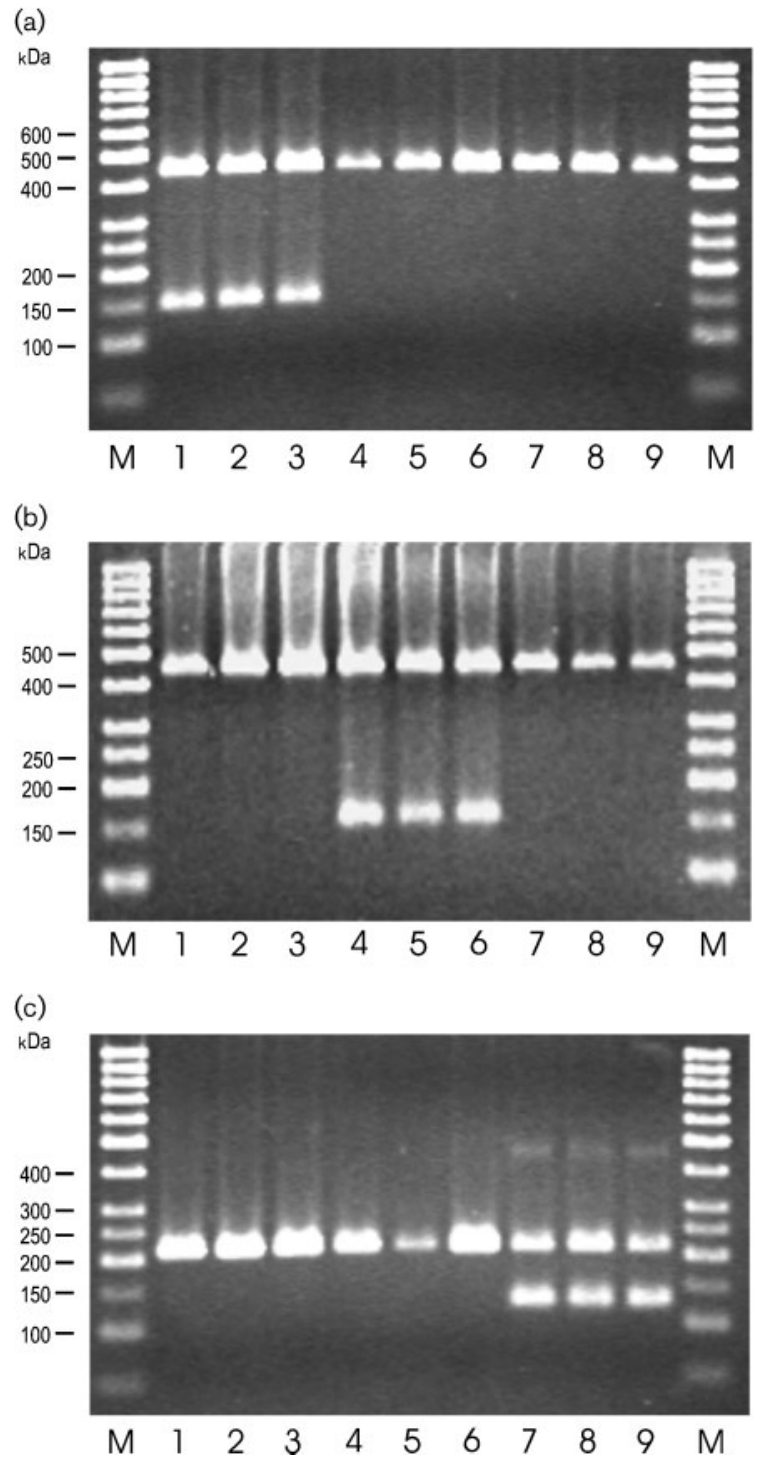

Fig. 1. Results of biotype-specific PCRs for $P$. zopfii genotype 1 (a), $P$. zopfii genotype 2 (b) and $P$. blaschkeae sp. nov. (c) showing the specific products ( $P$. zopfii genotype 1, $150 \mathrm{bp}$; $P$. zopfii genotype 2, $165 \mathrm{bp} ; P$. blaschkeae, $126 \mathrm{bp}$ ) and the internal amplification controls ( $P$. zopfii genotypes 1 and 2, $450 \mathrm{bp}$; $P$. blaschkeae, $213 \mathrm{bp}$ ). Lanes: M, Marker; 1, P. zopfii genotype 1 RZI-1; 2, P. zopfii genotype 1 RZI-2; 3, P. zopfii genotype 1 SAG 2063; 4, P. zopfii genotype 2 SAG $2021 ; 5, P$. zopfii genotype 2 RZIl-2; 6 , P. zopfii genotype 2 RZII-3; 7, P. blaschkeae sp. nov. RZIII-1; 8, P. blaschkeae sp. nov. RZIII-2; 7, P. blaschkeae sp. nov. SAG $2064^{\top}$.

Comparison of the partial sequences of the $18 \mathrm{~S}$ rRNA genes revealed clear differences between the strains of the three current biotypes and all strains of each biotype were conspecific. The sequences of biotype 3 (strains RZIII-1, RZIII-2 and SAG 2064 ${ }^{\mathrm{T}}$; GenBank accession no. AY973041) clearly differed from those of biotypes 1 and 2 and had a sequence similarity of $98 \cdot 1 \%$ in the investigated 1442 bp of the $18 \mathrm{~S}$ 
rRNA gene. The sequences of biotype 2 (strains RZII-2, RZII-3, SAG 263-4 ${ }^{\mathrm{T}}$ and SAG 2021; AY940456) differed in some nucleotides from those of biotype 1 (strains RZI-1, RZI-2 and SAG 2063; AY973040) and had a sequence similarity of $99 \cdot 4 \%$ with biotype 1 . Phylogenetic analysis with the NJ method showed that all biotypes were most closely related to the other strains of $P$. zopfii and $P$. moriformis (Fig. 2a). Although the strains originated from

(a)

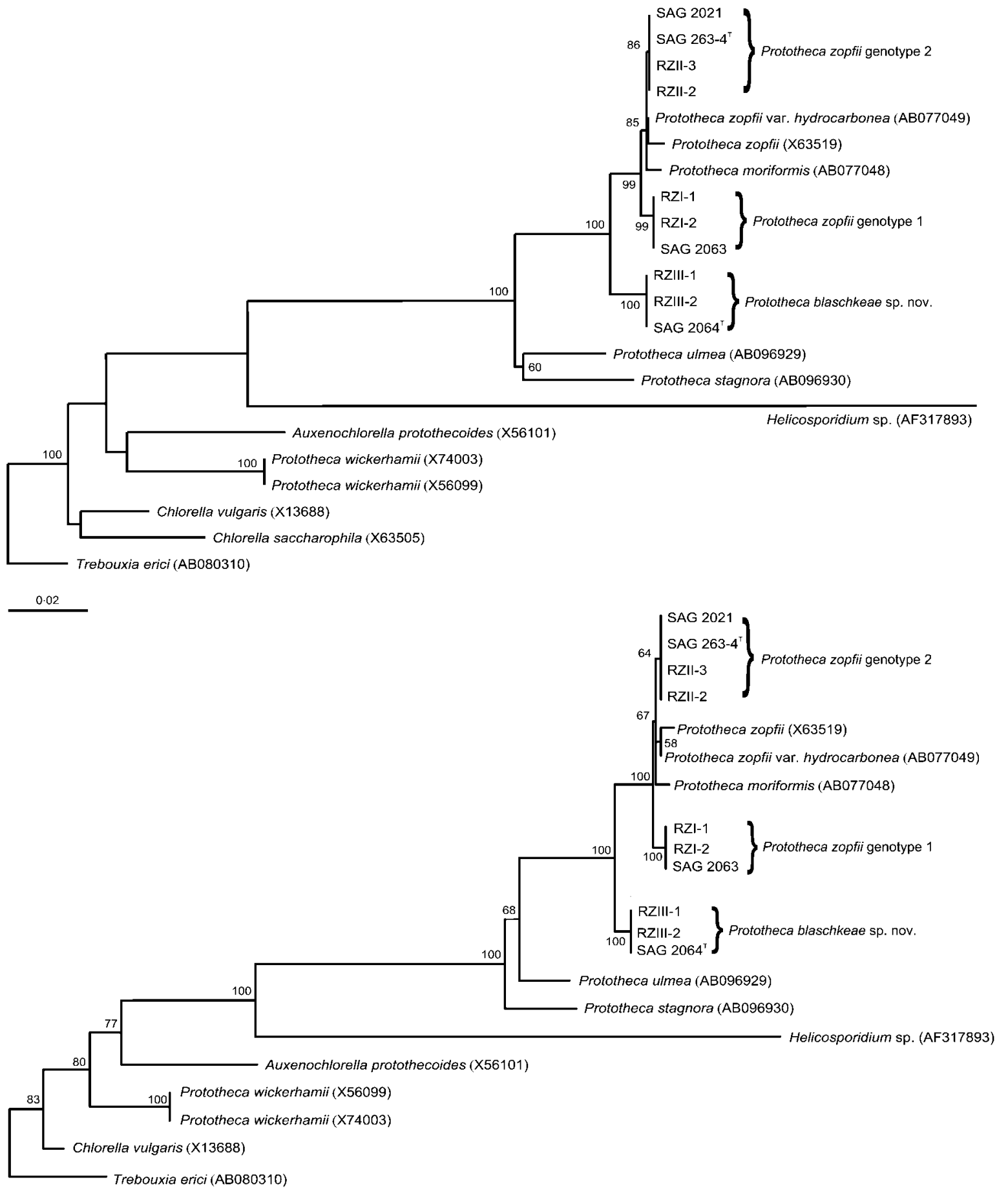

Fig. 2. Phylogenetic relationships of $P$. zopfii, $P$. blaschkeae sp. nov. and other recognized Prototheca species, based on 18S rRNA gene sequences. The trees were constructed using the NJ (a) and ML (b) methods. Numbers at nodes are percentage bootstrap frequencies derived from 1000 (NJ) or $100(\mathrm{ML})$ replicates. GenBank accession numbers are shown in parentheses. Bar, genetic distance between the strains analysed. 
epidemiologically different sources, the investigated strains of each biotype are clearly conspecific and form three distinct clades. Thereby, the strains of biotype 3 show the greatest phylogenetic distance from the other known $P$. $z$ opfii sequences, including the sequences of $P$. zopfii biotypes 1 and 2 . However, the investigated strains of biotypes 1 and 2 show a clearly smaller distance from strains of the P. zopfii clade. Thereby, biotype 1 differs more clearly than biotype 2 (Fig. 2a). The results obtained using the ML method were substantially the same (Fig. 2b).

The findings of previous serological, biochemical and morphological studies (Blaschke-Hellmessen et al., 1987, 1985; Roesler et al., 2003; Schmalreck et al., 1998) were confirmed by our biochemical and genetic results. One consequence of these results is the need to divide the species $P$. zopfii into at least two genotypes and the proposal of a novel Prototheca species.

One unanswered question is the assessment of the two established genotypes as two novel subspecies of P. zopfii. Strains of genotype 1 show marked biochemical and antigenic differences from other $P$. zopfii strains and furthermore form a well-supported phylogenetic clade. Because of the difficulty of biochemical identification, a possible subspecies name for the current biotype 1 could be Prototheca zopfii subsp. occulta. The subspecies status of genotype 2 of $P$. zopfii is strongly supported by typical disease-associated occurrence of the current biotype 2 in bovine mastitis, which has not yet been reported for the other biotypes (Schuster \& Blaschke-Hellmessen, 1983). Therefore, a possible name for this subspecies could be Prototheca zopfii subsp. bovimastitogenes. Furthermore, this genotype has obvious differences in antigenic pattern as well as in the pattern of cellular fatty acids. In contrast, based on $18 \mathrm{~S}$ rRNA gene sequences, the strains of this genotype are most closely related to other currently recognized $P$. zopfii strains, including $P$. moriformis. However, all investigated strains of biotype 2 are genetically conspecific and show marked differences from the other P. zopfii strains, which all show slight differences at the 18S rRNA gene level. In this context, it should be discussed whether the current genetically analysed strains of P. zopfii (e.g. P. zopfii var. hydrocarbonea) and P. moriformis also belong to different subspecies of $P$. zopfii. Our results clearly indicate that $P$. moriformis should be assigned to $P$. zopfii and does not represent an independent and valid species, supporting the results of Ueno et al. (2003). However, the known strains of $P$. moriformis have a strong heterogeneity in their biochemical characteristics, suggesting different taxonomic clusters within these strains.

Therefore, biotyping of the currently genetically analysed $P$. zopfii and P. moriformis strains is necessary and additional comparative sequence analyses of other genes, e.g. the largesubunit rRNA gene, are required to clarify the taxonomic status of these potential subspecies. Such studies are also necessary to elucidate the taxonomic position of $P$. wickerhamii. $P$. wickerhamii is more closely related to the genus Chlorella than to the genus Prototheca and should, therefore, be assigned to the genus Chlorella. This supports the phylogenetic relationships within the genus Prototheca reported by Ueno et al. (2003).

Proposed type strains for the described two genotypes of P. zopfii are SAG 2063 (GenBank accession no. AY973040) for P. zopfii genotype 1 and SAG 2021 (AY940456) for $P$. zopfii genotype 2, which have both been deposited in the Stammsammlung für Algenkulturen.

Finally, morphological results from the Fouriertransformed infra-red spectroscopy that showed distinct differences between biotype 3 and the other two biotypes (Schmalreck et al., 1998), the pattern of cellular fatty acids and the results of the sequence analysis indicate that the investigated isolates of the current biotype 3 of $P$. zopfii belong to a novel Prototheca species, Prototheca blaschkeae sp. nov.

\section{Latin diagnosis of Prototheca blaschkeae Roesler, Möller, Hensel, Baumann et Truyen sp. nov.}

In agaro Sabouraudii post 4 dies ad $37^{\circ} \mathrm{C}$, candida vel cremea, glabra, margo glabro vel undulato $(2 \mathrm{~mm})$. Textura molis. Sporangiosporae ovoideae aut globosae $(5-7 \cdot 5 \mu \mathrm{m})$ et sporangiae globosae $(15 \mu \mathrm{m})$. Ad $28^{\circ} \mathrm{C}$ et $37^{\circ} \mathrm{C}$ semper crescit. Glucosum, galactosum et fructosum assimilantur at non glycerolum, sorbitolum, arabinosum, lactosum, mannosum, melobiosum, rhamnosum, sucrosum et trehalosum. Phenylalaninum et prolinum assimilantur at non lysinum, valinum et tetrazolium.

Typus RZIII- $3^{\mathrm{T}}$ (=SAG $2064^{\mathrm{T}}$ ), ex onychomycosi hominis, Dresden, Germania, R. Blaschke-Hellmessen isolatus est. In collectione Stammsammlung für Algenkulturen, Universitas Göttingen, Göttingen, Germania, SAG $2064^{\mathrm{T}}$ deposita est.

\section{Description of Prototheca blaschkeae Roesler, Möller, Hensel, Baumann \& Truyen sp. nov.}

Prototheca blaschkeae (bla.sch'ke.ae. N.L. gen. n. blaschkeae in honour of Professor Renate Blaschke-Hellmessen, Dresden, Germany, who first described the occurrence of different 'variants' of $P$. zopfii).

After 4 days incubation on Sabouraud dextrose agar at $37^{\circ} \mathrm{C}$, colonies are white to cream, smooth, convex and have a mean diameter of $2 \mathrm{~mm}$. Texture of colonies is soft and viscous. Form small, ovoid to globose $(5-7 \cdot 5 \mu \mathrm{m})$ sporangiospores in sporangias, with a mean diameter of $15 \mu \mathrm{m}$ (Fig. 3). Good growth occurs at 28 and $37^{\circ} \mathrm{C}$. Glucose, galactose and fructose are assimilated, but not glycerol, sorbitol, arabinose, lactose, mannose, melobiose, rhamnose, sucrose or trehalose. Phenylalanine and proline are assimilated, but not lysine, valine or tetrazolium.

The type strain, RZIII- $3^{\mathrm{T}}$, was isolated from a human case of onychomycosis in Dresden, Germany, by R. BlaschkeHellmessen and has been deposited in the Stammsammlung 

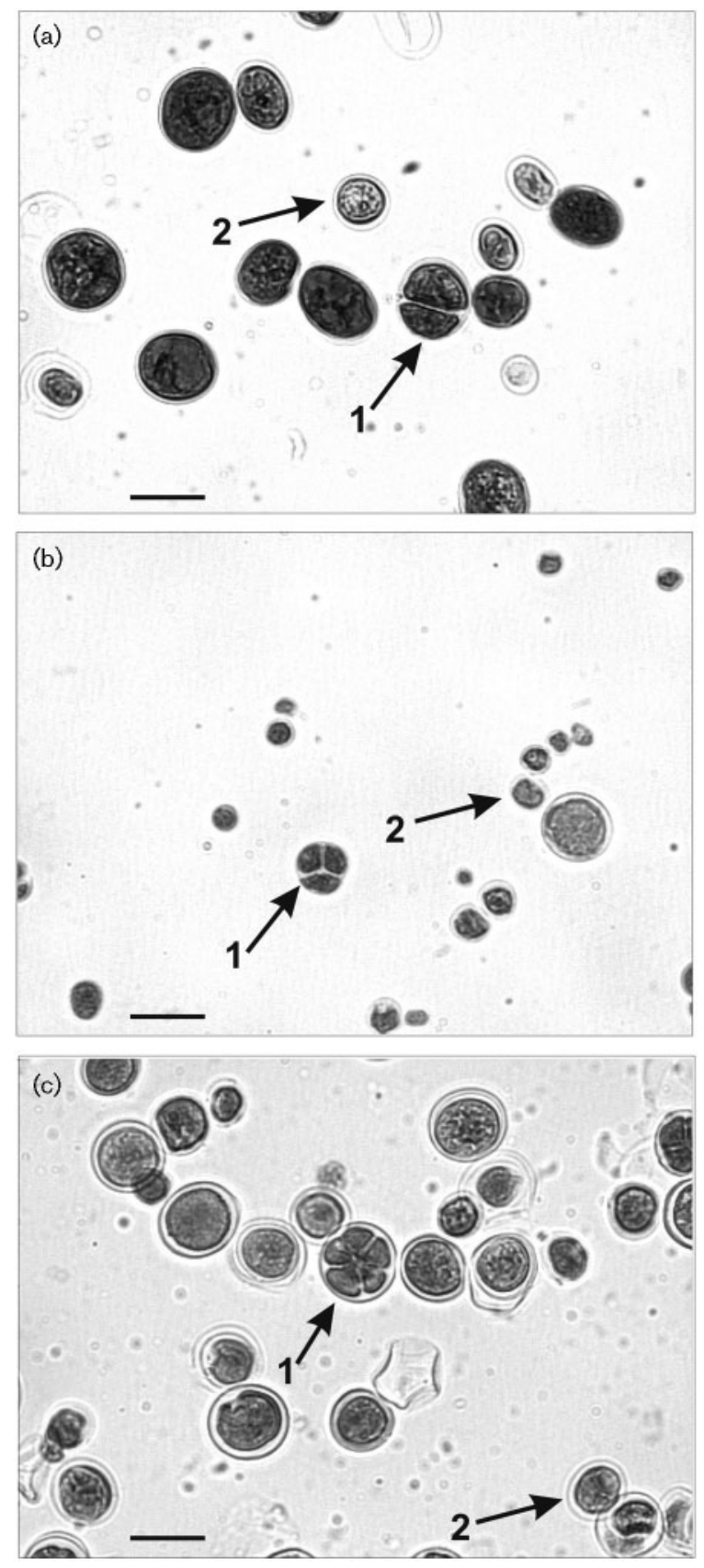

Fig. 3. Light micrographs of cells of $P$. zopfii genotype $1 \mathrm{SAG}$ 2063 (a), P. zopfii genotype 2 SAG 2021 (b) and $P$. blaschkeae sp. nov. SAG $2064^{\top}$ (c) stained with lactophenol cotton blue. Arrows indicate sporangia (1) and released sporangiospores (2). The cultures were photographed after an incubation period of $48 \mathrm{~h}$ at $37^{\circ} \mathrm{C}$ on Sabouraud dextrose agar plates. $P$. zopfii genotype 2 SAG 2021 forms substantially smaller daughter cells (sporangiospores), with a diameter of about $5 \mu \mathrm{m}$. In contrast, sporangiospores of $P$. zopfii genotype 1 SAG 2063 and P. blaschkeae SAG $2064^{\top}$ are approximately $10 \mu \mathrm{m}$ in size. Bars, $15 \mu \mathrm{m}$. für Algenkulturen, University of Göttingen, Göttingen, Germany, as SAG $2064^{\mathrm{T}}$. Reference strains are RZIII-1 and RZIII-2.

Micrographs of P. blaschkeae SAG $2064^{\mathrm{T}}$, P. zopfii genotype 1 SAG 2063 and P. zopfii genotype 2 SAG 2021 are shown in Fig. 3.

\section{Acknowledgements}

Evelin Brumme and Nadja Leinecker are gratefully acknowledged for their expert technical assistance. Maike Lorenz and Werner Reißer are gratefully acknowledged for critical reading of the manuscript.

\section{References}

Arnold, P. \& Ahearn, D. G. (1972). The systematics of the genus Prototheca with a description of a new species P. filamenta. Mycologia 64, 265-275.

Biedermann, W., Lücker, E., Pörschmann, J., Lachhab, S., Truyen, U. \& Hensel, A. (2004). Structural characterisation of some fatty acids from the brain as biomarkers of BSE risk material. Anal Bioanal Chem 379, 1031-1038.

Blaschke-Hellmessen, R., Schuster, H. \& Bergmann, V. (1985). Differenzierung von Varianten bei Prototheca zopfii (Krüger 1894). Arch Exp Veterinarmed 39, 387-397 (in German).

Blaschke-Hellmessen, R., Wilhelm, A., Teichmann, G., Schuster, H. \& Boeltzig, K. (1987). Orientierende Untersuchungen zum Nachweis von Antikörpern gegen Prototheca zopfii bei Rindern. Monatsh Veterinarmed 42, 48-50 (in German).

Felsenstein, J. (1985). Confidence limits on phylogenies: an approach using the bootstrap. Evolution 39, 783-791.

Jobb, G., von Haeseler, A. \& Strimmer, K. (2004). TREEFINDER: a powerful graphical analysis environment for molecular phylogenetics. BMC Evol Biol 4, 18.

Kimura, M. (1980). A simple method for estimating evolutionary rates of base substitutions through comparative studies of nucleotide sequences. J Mol Evol 16, 111-120.

Krüger, W. (1894). Kurze Charakteristik einiger niederer Organismen im Saftflusse der Laubbäume. Hedwigia XXXIII, 16-241 (in German).

Pore, R. S. (1985). Prototheca taxonomy. Mycopathologia 90, 129-139.

Pore, R. S. (1986). The association of Prototheca spp. with slime flux in Ulmus amencana and other trees. Mycopathologia 94, 67-73.

Roesler, U., Scholz, H. \& Hensel, A. (2001). Immunodiagnostic identification of dairy cows infected with Prototheca zopfii at various clinical stages and discrimination between infected and uninfected cows. J Clin Microbiol 39, 539-543.

Roesler, U., Scholz, H. \& Hensel, A. (2003). Emended phenotypic characterization of Prototheca zopfii: a proposal for three biotypes and standards for their identification. Int J Syst Evol Microbiol 53, 1195-1199.

Saitou, N. \& Nei, M. (1987). The neighbor-joining method: a new method for reconstructing phylogenetic trees. Mol Biol Evol 4, 406-425.

Schmalreck, A. F., Trankle, P., Vanca, E. \& BlaschkeHellmessen, R. (1998). Differenzierung und Charakterisierung von humanpathogenen Hefen (Candida albicans, Exophiala dermatidis) und tierpathogenen Algen (Prototheca spp.) mittels FourierTransform-Infrarot-Spektroskopie (FT-IR) im Vergleich zu konventionellen Methoden. Mycoses 41 (Suppl. 1), 71-77 (in German). 
Schuster, H. \& Blaschke-Hellmessen, R. (1983). Zur Epidemiologie der Protothekenmastitis des Rindes - Anzüchtung von Algen der Gattung Prototheca aus der Umgebung landwirtschaftlicher Nutztiere. Monatsh Veterinarmed 38, 24-29 (in German).

Thompson, J. D., Higgins, D. G. \& Gibson, T. J. (1994). ClustaL W: improving the sensitivity of progressive multiple sequence alignment through sequence weighting, position-specific gap penalties and weight matrix choice. Nucleic Acids Res 22, 4673-4680.
Ueno, R., Urano, N. \& Suzuki, M. (2003). Phylogeny of the nonphotosynthetic green micro-algal genus Prototheca (Trebouxiophyceae, Chlorophyta) and related taxa inferred from SSU and LSU ribosomal DNA partial sequence data. FEMS Microbiol Lett 223, 275-280.

Van de Peer, Y. \& De Wachter, R. (1994). TREECON for Windows: a software package for the construction and drawing of evolutionary trees for the Microsoft Windows environment. Comput Appl Biosci 10, 569-570. 